\title{
Structure and optical anisotropy of vertically correlated submonolayer InAs/GaAs quantum dots
}

Xu, Zhangcheng; Birkedal, Dan; Hvam, Jørn Märcher; Zhao, Z.Y.; Liu, Y.M.; Yang, K.T.; Kanjilal, A.; Sadowski, J.

Published in:

Applied Physics Letters

Link to article, DOI:

$10.1063 / 1.1581005$

Publication date:

2003

Document Version

Publisher's PDF, also known as Version of record

Link back to DTU Orbit

Citation (APA):

Xu, Z., Birkedal, D., Hvam, J. M., Zhao, Z. Y., Liu, Y. M., Yang, K. T., Kanjilal, A., \& Sadowski, J. (2003).

Structure and optical anisotropy of vertically correlated submonolayer InAs/GaAs quantum dots. Applied Physics Letters, 82(22), 3859-3861. https://doi.org/10.1063/1.1581005

\section{General rights}

Copyright and moral rights for the publications made accessible in the public portal are retained by the authors and/or other copyright owners and it is a condition of accessing publications that users recognise and abide by the legal requirements associated with these rights.

- Users may download and print one copy of any publication from the public portal for the purpose of private study or research.

- You may not further distribute the material or use it for any profit-making activity or commercial gain

- You may freely distribute the URL identifying the publication in the public portal 


\title{
Structure and optical anisotropy of vertically correlated submonolayer InAs/GaAs quantum dots
}

\author{
Zhangcheng $\mathrm{Xu}^{\text {a) }}$ Dan Birkedal, and Jørn M. Hvam \\ Research Center COM, Technical University of Denmark, DK-2800, Lyngby, Denmark \\ Zongyan Zhao, Yanmei Liu, and Kuntang Yang \\ Department of Physics, Anhui University, Hefei, 230039, People's Republic of China \\ Aloke Kanjilal \\ Department of Physics, University of Aarhus, Ny Munkegde, DK-8000, Aarhus C, Denmark \\ Janusz Sadowski \\ Niels Bohr Institute, Copenhagen University, DK-2100, Copenhagen, Denmark
}

(Received 16 September 2002; accepted 21 April 2003)

\begin{abstract}
A vertically correlated submonolayer (VCSML) InAs/GaAs quantum-dot (QD) heterostructure was studied using transmission electron microscopy, high-resolution x-ray diffraction (HRXRD) and polarization-dependent photoluminescence. The HRXRD (004) rocking curve was simulated using the Tagaki-Taupin equations. Excellent agreement between the experimental curve and the simulation is achieved assuming that indium-rich VCSML QDs are embedded in a quantum well (QW) with lower indium content and an observed QD coverage of 10\%. In the VCSML QDs, the vertical lattice mismatch of the InAs monolayer with respect to GaAs is around $1.4 \%$, while the lattice mismatch in the QW is negligible. The photoluminescence is transverse magnetic-polarized in the edge geometry. (C) 2003 American Institute of Physics. [DOI: 10.1063/1.1581005]
\end{abstract}

Much interest has been attracted to the growth of selfassembled semiconductor quantum dots (QDs), due to their potential application in optoelectronic devices. ${ }^{1}$ Submonolayer (SML) deposition is an alternative method to the widely used Stranski-Krastanow (SK) mode of growing QDs. ${ }^{2-4}$ Deposition of a SML InAs on a GaAs (001) surface leads to the formation of $1 \mathrm{ML}$ high InAs islands elongated along the $[1 \overline{1} 0]$ direction. ${ }^{2}$ The density and the lateral sizes of the islands depend on the deposition amount. Vertical correlation of the SML QDs occurs when stacking the SLM QDs with thin spacers. ${ }^{5-9}$ High-power lasers with the stacked SML InAs/GaAs QDs as the active region have recently been demonstrated. ${ }^{6-8}$ The structure and optical properties of the SK InAs/GaAs QDs have been intensively studied, ${ }^{1}$ but few papers have been reporting on the vertically correlated (VC) SML InAs/GaAs QDs. ${ }^{4,9}$ In this letter, the structure and the optical anisotropy of the VCSML InGaAs QDs are investigated by plan-view transmission electron microscopy (TEM), high-resolution x-ray diffraction (HRXRD), and polarization-dependent photoluminescence (PL) at low temperature in both the backscattering and the edge emission geometries.

The VCSML InAs/GaAs QD sample was molecularbeam epitaxy grown on a semi-insulating GaAs (001) substrate. After oxide desorption, a $500 \mathrm{~nm}$ GaAs buffer layer, $20 \mathrm{~nm} \mathrm{AlAs}$, and $82 \mathrm{~nm} \mathrm{GaAs}$ were grown at $600{ }^{\circ} \mathrm{C}$. After the substrate temperature was lowered to $480^{\circ} \mathrm{C}, 10$ cycles of $\operatorname{InAs}(0.5 \mathrm{ML}) / \mathrm{GaAs}(2.5 \mathrm{ML})$ were deposited to form a VCSML QD layer, with $2 \mathrm{~nm}$ of GaAs covering the VCSML QD layer. Then, the substrate temperature was again in-

a)Electronic mail: zxu@com.dtu.dk creased to $600{ }^{\circ} \mathrm{C}$ to grow $20 \mathrm{~nm}$ of $\mathrm{AlAs}$ and a $106 \mathrm{~nm}$ GaAs cap layer.

TEM studies were performed using a Philips CM20 instrument operating at $200 \mathrm{keV}$. Figure 1 shows a plan-view TEM image of the VCSML InAs/GaAs QDs. The contrast is mainly due to strain fields. $10 \%$ of the surface is covered by QDs and the area density of QDs is around 5.2 $\times 10^{11} \mathrm{~cm}^{-2}$, much higher than the conventional SK InAs/ GaAs QDs. Most of the QDs are slightly elongated along [1 $1 \overline{1} 0]$ direction, and the size of QDs is around 5-10 $\mathrm{nm}$ in diameter. However, the actual QD size could be smaller since the strain field may extend beyond the QD boundary.

The determination of the strain in the QDs is useful not only for understanding the QD growth but also for the calculation of the energy diagram of the QDs. ${ }^{5,10,11}$ HRXRD is

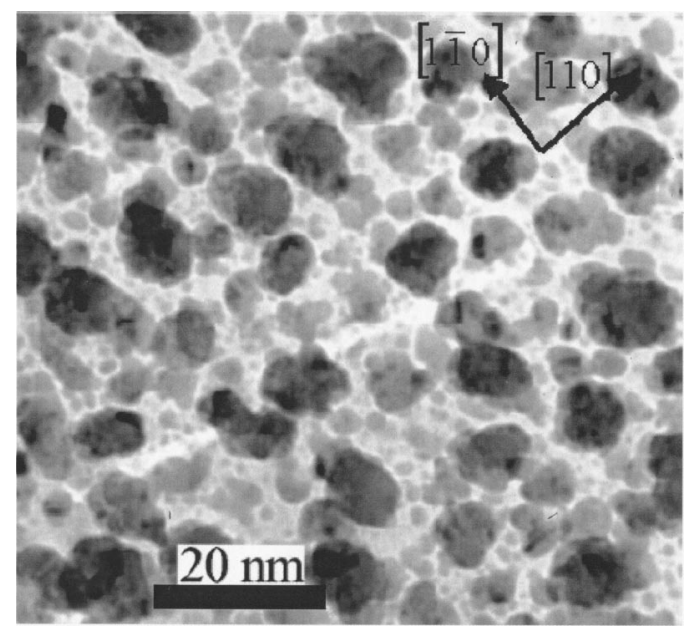

FIG. 1. (011) bright-field plan-view TEM image of the structure with VCSML InAs/GaAs QDs. 


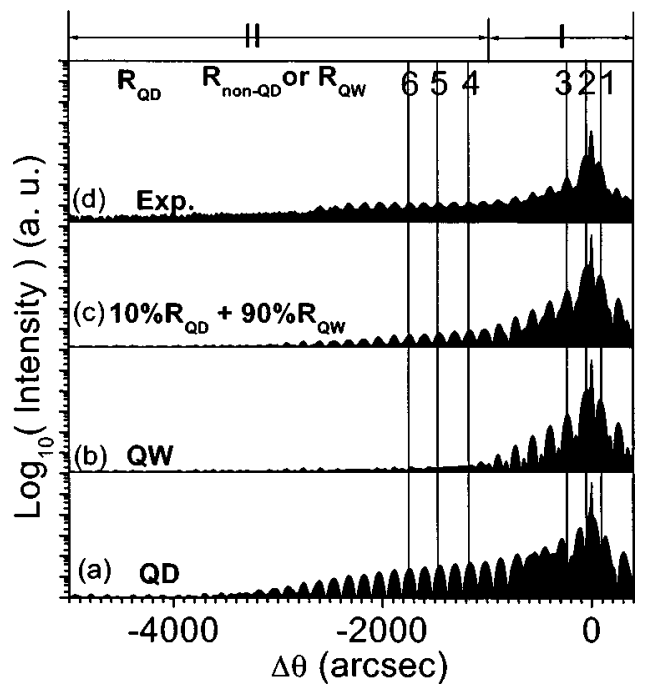

FIG. 2. HRXRD rocking curves in the vicinity of the GaAs (004) refection, (a) the simulated curve of $R_{\mathrm{QD}}$, assuming $a_{\mathrm{InAs}}^{\perp}=5.7324 \AA$, (b) the simulated curve of $R_{\mathrm{QW}}$, assuming $a_{\mathrm{In}_{0.15} \mathrm{Ga}_{0.85} \mathrm{As}}^{\perp}=5.6533 \AA$, and (c) the combination of (a) and (b), assuming the QD coverage percentage is $10 \%$, and (d) the experimental data. The curves are shifted vertically for clarity. The inset shows the different contributions from the QD parts and the lateral non-QD parts to the reflection coefficient of a VCSML QD sample. Lines 1 to 6 are guides for the eyes.

an important nondestructive method of determining the interface morphology and the strain of the buried films. The measured rocking curves are the "fingerprints" of the investigated structure and can be analyzed by using the dynamical $\mathrm{x}$-ray diffraction theory, i.e., the Tagaki-Taupin equations. ${ }^{11,12}$ Due to the structural complexity of a QD heterostructure, the average strain of the QD plane rather than of the QDs themselves has been determined for the SK QDs. ${ }^{13-15}$ In the case of the VCSML QDs, the contribution from the QD parts and the lateral non-QD parts to the finally measured reflection rocking curve can be considered separately, as shown in the inset of Fig. 2. According to the growth mechanism of stacked SML InGaAs QD heterostructure, ${ }^{7}$ the VCSML QD in our sample can be described as 10 cycles of $\mathrm{GaAs}(2 \mathrm{ML}) / \mathrm{InAs}(1 \mathrm{ML})$, while the lateral non-QD part can be described as a $30 \mathrm{ML} \mathrm{GaAs}$ and $50 \%$ of the surface should be covered by the VCSML QDs. However, QDs only fill about $10 \%$ of the surface in the planview TEM image (Fig. 1). This means that $40 \%$ of the SML InAs is in the lateral non-QD part, possibly due to In-Ga intermixing or because vertical correlation does not occur for all the SML QDs. Therefore, the lateral non-QD part is an InGaAs alloy rather than pure GaAs, and our sample is a QD-quantum-well (QW) heterostructure. The average In composition in the lateral $\mathrm{QW}$ is calculated to be around $15 \%$, according to the $10 \%$ QD coverage on the surface.

The HRXRD rocking curve near the (004) reflection peak of GaAs (001) substrate was measured using a MAC Science HRXRD instrument with a $\mathrm{Cu} K \alpha$ x-ray source and a Ge (004) monochromator. Figure 2 shows the experimental data and simulated results based on Tagaki-Taupin equations. The total reflection coefficient $R(\Delta \theta)$ of the sample can be written as where $\Delta \theta$ is the angular deviation from the Bragg angle of the (004) peak of the GaAs substrate, $x$ is the QD coverage percentage on the surface, $R_{\mathrm{QD}}(\Delta \theta)$ and $R_{\mathrm{QW}}(\Delta \theta)$ are the reflection coefficients from the part of the sample with only the VCSML QDs and the part with only the lateral QW, respectively. Note that Eq. (1) is valid only when $x R_{\mathrm{QD}}(\Delta \theta)$ is so small that the multiple scattering of $x$ rays between the QD and the QW parts is negligible. In the angular range from -1000 to +500 arcs (range I), the reflectivity is much higher than outside this range and mainly depends on the $R_{\mathrm{QW}}(\Delta \theta)$ because QW covers $90 \%$ of the surface. Only when the lattice mismatch is negligible between the lateral $8.48 \mathrm{~nm} \mathrm{In}_{0.15} \mathrm{Ga}_{0.85} \mathrm{As} \mathrm{QW}$ and GaAs, do the calculated interference fringes [curve b in Fig. 2(b), lines 1 to 3] match the experimental ones in range I. At the same time, no inference fringes in the range from -1000 to -4000 (range II) in curve $b$ can be comparable to the experimental data. Therefore, the interference fringes in range II are mainly from $R_{\mathrm{QD}}(\Delta \theta)$. By varying the lattice constant $a_{\mathrm{InAs}}^{\perp}$ of the InAs monolayer inside the VCSML QDs, $R_{\mathrm{QD}}(\Delta \theta)$ is calculated and found to match the interference fringes [curve a in Fig. 2(a), lines 4 to 6] only when $a_{\mathrm{InAs}}^{\perp} \approx 5.7324 \AA$, i.e., $a_{\mathrm{InAs}}^{\perp}$ is around $1.4 \%$ higher than the lattice constant of GaAs. With $x=10 \%$ determined from the TEM image (Fig. 1), curve $\mathrm{c}$ in Fig. 2(c) is calculated from Eq. (1). It can be seen that all the interference fringes in curve $\mathrm{c}$ in Fig. 2(c) can match the experimental ones very well. The macroscopic continuum elasticity theory (MCET) predicts that for a pseudomorphic InAs layer buried in GaAs (001), the strain normal to the (001) plane would be $7.26 \%$, corresponding to $a_{\mathrm{InAs}}^{\perp}$ $\approx 6.4981 \AA .{ }^{16,17}$ However, the validity of the MCET in the monolayer limit is a long debated issue. ${ }^{18-20}$ In the case of SML InAs QDs, the InAs islands with 1 monolayer in height and around 5-10 $\mathrm{nm}$ in diameter are surrounded by a GaAs matrix, and the MCET cannot be applied directly. Our HRXRD gives an experimental determination of the strain in the SML InAs QDs.

Shape anisotropy effects on the electronic properties of VCSML InAs/GaAs QDs are investigated here by measuring the polarization dependence of the optical transitions. The PL was excited at $10 \mathrm{~K}$ by a $\mathrm{He}-\mathrm{Ne}$ laser at $632.8 \mathrm{~nm}$ with an excitation density $\sim 10 \mathrm{~W} / \mathrm{cm}^{2}$. A $64 \mathrm{~cm}$ monochromator with a Si charge coupled device was used to detect the PL. The polarization of the PL was analyzed using a fixed polarizer and a broadband $\lambda / 2$ plate. The PL polarization anisotropy is defined as $P=\left(I_{\|}-I_{\perp}\right) /\left(I_{\|}+I_{\perp}\right)$, where $I_{\perp}$ is the vertically polarized intensity and $I_{\|}$is the horizontally polarized intensity in the laboratory coordinate system.

Figure 3 shows the degree of linear polarization of PL detected in both the backscattering [curve (a) in Fig. 3(a)] and the edge geometries [curves (b) and (c) in Figs. 3(b) and $3(\mathrm{c})$, respectively]. In the backscattering geometry, the light propagates in the [001] direction (surface emission), $I_{\|}$and $I_{\perp}$ are polarized along the [1 $\left.\overline{10}\right]$ and [110] directions, respectively. The broad peak [curve (d) in Fig. 3(d)] centered at $1.26 \mathrm{eV}$ with a linewidth of $55 \mathrm{meV}$ is assigned to the ground-state transitions of the VCSML InAs/GaAs QDs. PL emission from the QDs is predominantly polarized along the [1 $1 \overline{1} 0$ ] direction in the whole energy range, $P \approx 0.22$ [curve (a) in Fig. 3(a)], due to the elongation of the QDs along the o AIP license or copyright; see http://apl.aip.org/apl/copyright.jsp 


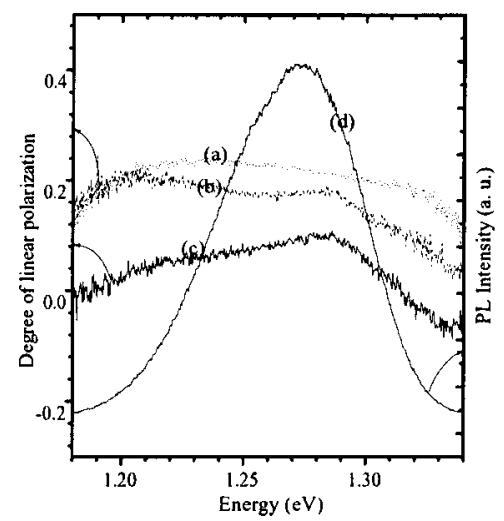

FIG. 3. The degree of linear polarization of PL measured at $10 \mathrm{~K}$, (a) in the backscattering geometry, collecting light in the [001] direction, (b) in the edge geometry, collecting light in the [1 $1 \overline{1} 0]$ direction, and (c) in the edge geometry, collecting light in the [110] direction. Curve (d) is a PL spectrum measured in the backscattering geometry, polarized along the [1 $\overline{1} 0]$ direction.

[1 10$]$ direction, as shown in the plan-view TEM observation.

In the edge geometry, the spectra were obtained exciting and detecting at the sample edges, the light propagates in [110] or [1 $\overline{1} 0]$ direction, $I_{\|}$and $I_{\perp}$ are polarized along the $[001]$ and $[1 \overline{1} 0]$ or $[110]$ directions, respectively. These polarizations are, respectively, referred to as transverse magnetic (TM) and transverse electric (TE) modes. To suppress the PL emission from the [001] sample surface, the edge emission was spatially selected in near and far field. From curves (b) and (c) of Figs. 3(b) and 3(c), respectively, the PL emission was found to be TM polarized in the VCSML InGaAs/GaAs QDs, while a single-layer InGaAs/GaAs SK QD structure shows a TE polarization, measured in the same geometry and using similar equipment. This indicates that the electronic states are elongated along the growth direction for VCSML InGaAs/GaAs QDs. A similar result has been observed in the case of vertically coupled CdSe/ZnSSe SML QDs and InGaAs/GaAs SK QDs. ${ }^{4,21}$ A slightly higher anisotropy of $P \approx 0.17$ for emission along the [1 10$]$ direction [curve (b) in Fig. 3(b)] than that of $P \approx 0.09$ along the [110] direction [curve (c) in Fig. 3(c)] is due to the fact that the lateral dimensions of VCSML QDs along [1 $\overline{1} 0]$ direction are nearer to the QD heights. This feature is not only of the fundamental interest for electronic structure and optical properties, but also important in its applications in polarization-independent devices.

In summary, the structure and optical anisotropy of VCSML InAs/GaAs QDs, are studied using plan-view TEM, HRXRD, and polarization-dependent PL at low temperature in both the backscattering and edge geometries. The method of calculating the reflection coefficient from a VCSML QD heterostructure was demonstrated, using the Tagaki-Taupin equations, the structure of VCSML QDs, and the QD coverage percentage on the surface. The separate contributions from the QDs and the lateral QW to the total x-ray diffraction signal have been extracted. The lattice mismatch in the InAs monolayer inside the VCSML is found to be around $1.4 \%$ with respect to $\mathrm{GaAs}$, and that in the lateral $\mathrm{QW}$ is negligible. In the edge geometry, the PL emission is TM polarized, which is important for the application of VCSML QDs in optoelectronic devices.

This work was supported by the Danish Technical Science Research Council.

${ }^{1}$ D. Bimberg, M. Grundmann, and N. N. Ledentsov, Quantum Dot Heterostructures (Wiley, New York, 1999).

${ }^{2}$ V. Bressler-Hill, A. Lorke, S. Varma, P. M. Petroff, K. Pond, and W. H. Weinberg, Phys. Rev. B 50, 8479 (1994).

${ }^{3}$ N. N. Ledentsov, I. L. Krestnikov, M. Strabburg, R. Engelhardt, S. Rodt, R. Heitz, U. W. Pohl, A. Hoffmann, D. Bimberg, A. V. Sakharov, W. V. Lundin, A. S. Usikov, Z. I. Alferov, D. Litvinov, A. Rosenauer, and D. Gerthsen, Thin Solid Films 367, 40 (2000).

${ }^{4}$ I. L. Krestnikov, N. N. Ledentsov, A. Hoffmann, and D. Bimberg, Phys. Status Solidi A 183, 207 (2001).

${ }^{5}$ V. A. Shchukin and D. Bimberg, Rev. Mod. Phys. 71, 1125 (1999).

${ }^{6}$ A. F. Zhukov, A. R. Kovsh, S. S. Mikhrin, N. A. Maleev, V. M. Ustinov, D. A. Livshits, I. S. Tarasov, D. A. Bedarev, M. V. Maximov, A. F. Tsatsulnikov, I. P. Soshnikov, P. S. Kopev, Z. I. Alferov, N. N. Ledentsov, and D. Bimberg, Electron. Lett. 35, 1845 (1999).

${ }^{7}$ S. S. Mikhrin, A. E. Zhukov, A. R. Kovsh, N. A. Maleev, V. M. Ustinov, Y. M. Shernyakov, I. P. Soshnikov, D. A. Livshits, I. S. Tarasov, D. A. Bedarev, B. V. Volovik, M. V. Maximov, A. F. Tsatsulnikov, N. N. Ledentsov, P. S. Kopev, D. Bimberg, and Z. I. Alferov, Semicond. Sci. Technol. 15, 1061 (2000).

${ }^{8}$ S. S. Mikhrin, A. R. Kovsh, A. E. Zhukov, D. A. Livshits, N. A. Maleev, A. P. Vasil'eV, Y. M. Shernyakov, M. V. Maximov, N. A. Pihtin, I. S. Tarasov, V. M. Ustinov, N. N. Ledentsov, D. Bimberg, and Z. I. Alferov, Abstract of the 26th International Conference on the Physics of Semiconductors, 29 July-2 August 2002 (Edinburgh, UK), L2.3.

${ }^{9}$ A. F. Tsatsul'nikov, B. V. Volovik, N. N. Ledentsov, M. V. Maximov, A. Y. Egorov, A. R. Kovsh, V. M. Ustinov, A. E. Zhukov, P. S. Kop'ev, Z. I. Alferov, I. A. Kozin, M. V. Belousov, I. P. Soshnikov, P. Werner, D. Litvinov, U. Fischer, A. Rosenauer, and D. Gerthsen, J. Electron. Mater. 28, 537 (1999).

${ }^{10}$ H. Schmidt, R. Pickenhain, and G. Böhm, Phys. Rev. B 65, 045323 (2002).

${ }^{11}$ K. Shiraishi and E. Yamaguchi, Phys. Rev. B 42, 3064 (1990).

${ }^{12}$ S. Takagi, Acta Crystallogr. 15, 1311 (1962).

${ }^{13}$ D. Taupin, Bull. Soc. Fr. Mineral. Cristallogr. 87, 469 (1964).

${ }^{14}$ A. Krost, F. Heinrichsdorff, D. Bimberg, A. Darhuber, and G. Bauer, Appl. Phys. Lett. 68, 785 (1995).

${ }^{15}$ D. Pal, E. Towe, and S. Chen, Appl. Phys. Lett. 78, 4133 (2001).

${ }^{16}$ J. Hornstra and W. J. Bartels, J. Cryst. Growth 44, 513 (1978).

${ }^{17}$ D. M. Wood and A. Zunger, Phys. Rev. B 40, 4062 (1989).

${ }^{18}$ O. Brandt, K. Ploog, R. Bierwolf, and M. Hohenstein, Phys. Rev. Lett. 64, 36 (1992).

${ }^{19}$ J. E. Bernard and A. Zunger, Appl. Phys. Lett. 65, 165 (1994).

${ }^{20}$ T. L. Lee, M. R. Pillai, J. C. Woicik, G. Labanda, P. F. Lyman, S. A. Barnett, and M. J. Bedzyk, Phys. Rev. B 60, 13612 (1999).

${ }^{21}$ P. Yu, W. Langbein, K. Leosson, J. M. Hvam, N. N. Ledentsov, D. Bimberg, V. M. Ustinov, A. Y. Egorov, A. E. Zhukov, A. F. Tsatsul'nikov, and Y. G. Musikhin, Phys. Rev. B 60, 16680 (1999). 